\title{
Third National Health and Nutrition Examination Survey
}

National Cancer Institute

\section{Source}

National Cancer Institute. Third National Health and Nutrition Examination Survey. NCI

Thesaurus. Code C81824.

A survey conducted between 1988 and 1994 on a nationwide probability sample of approximately 33,994 persons, age 2 months and over. The survey was designed to obtain nationally representative information on the health and nutritional status of the population of the United States through interviews and direct physical examinations. 